\title{
Guías clínicas de enfermería neurológica y planes de cuidados de enfermería neurológica, neurocirugía y neuropsiquiatría
}

Las guías clínicas de enfermería neurológica I, señalan la relevancia que la profesión cobra en el Instituto Nacional de Neurología y Neurocirugía, son una aportación para la disciplina en la atención y cuidado que se brinda a la persona con problemas neurológicos o que tienen relación con las neurociencias, estas guías favorecen la calidad de atención y la mejor satisfacción en las personas que requieren cuidado especializado. Están coordinadas por la MRN. Rocio Valdez Labastida Subdirectora de Enfermería y la M. en Admón. Patricia Zamora Ruíz Coordinadora Clínica; ofrecen temas innovadores de acuerdo a los indicadores de calidad con el propósito de evaluar los servicios de enfermería en su dimensión técnica e interpersonal. Integradas por: La guía Trato Digno presentada por Ma. Guadalupe Nava Galán, Evento Adverso presentada por Beatriz Trejo Casañas. Prevención de Caídas por Patricia Zamora Ruíz, Nayeli Delgado Cobarrubias y Edith Vilchis Mora; Administración de Medicamentos vía oral e intravenosa por Dolores García Salinas; Prevención y Tratamiento de Úlceras por Presión la elabora Araceli Sánchez Ramos; Impregnación con Difenilhidantoina y Valproato de Magnesio a pacientes que presentan Crisis convulsivas tónico-clónicas generalizadas por Patricia Zamora Ruíz y

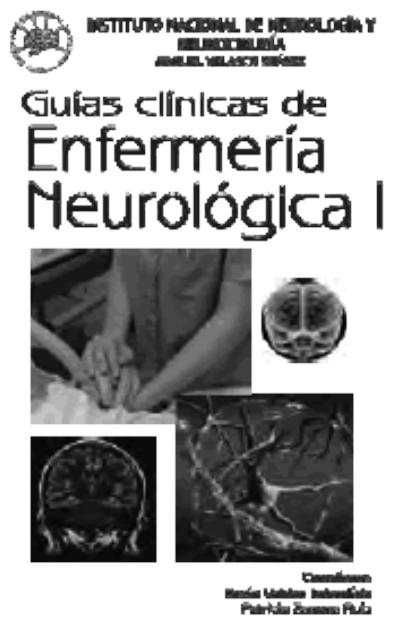
por Martha E. Castillo Trejo; Preparación de Anfotericina B en pacientes con Criptococosis por Montserrat Castelán Flores; Terapia Triple H por Magdalena Castillo Pérez; Neuronavegador por Alejandra Ibarra Rangel; Bolo de Metilprednisolona por Rosalba Reyes Araujo, Patricia Zamora Ruíz y Ana Lilia López Velásquez, estas guías muestran un marco teórico, referencial así como el procedimiento y flujograma de trabajo que desarrollan día a día los profesionales de enfermería del Instituto.

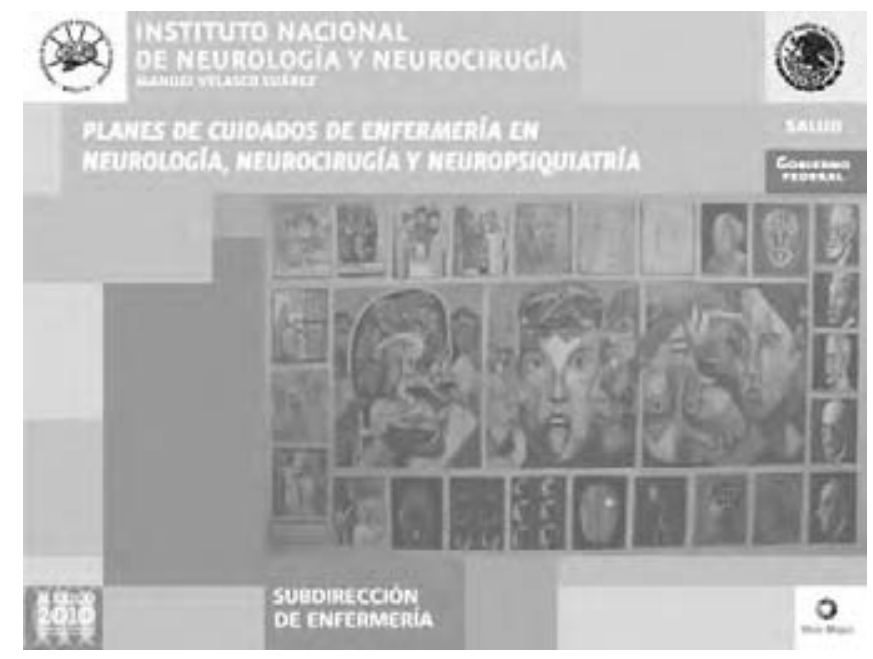

De la misma manera, se destaca la publicación paralelamente de los Planes de Cuidado en Enfermería, que ponen de manifiesto el compromiso de los profesionales que buscan favorecer el cuidado, de la más alta calidad y con el profesionalismo de acuerdo a los avances tecnológicos y científicos, que se enfrentan para proporcionar cuidado, la subdirección de enfermería de esté Instituto está a la vanguardia del conocimiento enfermero, por ello la Dirección de Enfermería de la Secretaría de Salud del Gobierno Federal, que coordina la Comisión Permanente de Enfermería y con reconocimiento como integrante del Comité Nacional por la Calidad de Salud, asumió el compromiso de trabajar en el proyecto de estandarización de los planes de cuidados de enfermería en respuesta a la directriz señalada en el Programa Nacional de Salud 2007-2010, respecto a la conveniencia de utilizar guías de práctica clínica y protocolos de atención como elementos indispensables para certificar la calidad de los servicios de salud y brindar seguridad a las personas atendidas en el INNN. Consecuencia de esto y de la Primera Jornada Técnica de Planes de Cuidados de Enfermería Estandarizados (PLACE'S) llevada a cabo en el 2008. La Dirección General de Calidad y Educación en Salud emitió la instrucción 103/2008 y con ello el compromiso público de Sicalidad para apoyar la institucionalización del Proceso Enfermero, a fin de profesionalizar el cuidado e incorporar a través del uso de sistemas estandarizados para identificar el estado de salud o los problemas de la persona, familia o comunidad, para poder prevenir, resolver o reducir mediante actividades independientes del profesional de enfermería. La 
Dirección de Enfermería ve la importancia para las instituciones de diseñar e implementar planes estandarizados de cuidados de enfermería como instrumento de trabajo diario, tiene como propósito llevar a cabo atención eficiente y eficaz estandarizada, estás se diseñan a partir de NANDA, NIC y NOC.

Estos planes también fueron coordinados por la subdirectora MRN Rocio Valdez Labastida y la M en Admón. Patricia Zamora Ruíz, Coordinadora Clínica; quien además de coordinar, elaboro en conjunto con el grupo de enfermeras expertas en neurología, neurocirugía y neuropsiquiatría: Angélica María de la Cruz Hernández, Olga Hernández Cruz e Irene Carrasco Palafox así como por Araceli Sánchez Ramos y Estela Pineda Ensaldo y por la Enf. Psiquiatra Maribel Pérez Martínez.

Se les hace extensivo el reconocimiento a quienes participaron en la elaboración de las Guías de Enfermería y de los Planes de cuidados, ya que su aportación es muy valiosa para los profesionales de enfermería del INNN y de otras instituciones de salud; así como, para todo aquel profesional que contribuya en la calidad sirviendo de apoyo para el cuidado especializado.

Lic. Enf. Ma. Guadalupe Nava Galán 